\title{
Applied Research on college Student Work Performance Evaluation Based on ANP
}

\author{
Miao $\operatorname{Tian}^{1}$ \\ International Education College, \\ Hebei Finance University, \\ Baoding, China
}

\author{
Yan-zi $\mathbf{L i}^{2}$ \\ International Education College, \\ Hebei Finance University, \\ Baoding, China
}

\begin{abstract}
Performance management refers to a system for management, control, decision-making and motivation in the process of integral management methods, it has been widely applied in all kinds of enterprises, research and education institutions and so on, but performance management theory in colleges and universities use the administrative work is significantly lagging behind. This paper based on the introduction of performance management theory, establish college students performance management evaluation system based on ANP model, provides an objective and feasible method for the college student work performance management.
\end{abstract}

Keywords: college students; Performance management; Evaluation system; ANP

\section{INTRODUCTION}

In the contemporary society, the essential factor of modern economic society development is the increasing of scientific and technological innovation. From the perspective of globalization, the competition of economic power and comprehensive national strength of every country is the competition of modern scientific and technological force. In the process of rapid development of science and technology, high quality personnel is the essential to enhance the strength of the country. College students management work is an important part of the internal management of the colleges and universities ,it is a critical foundation for higher school in long-term development whether survive or not. Therefore, in the modernization of our country colleges and universities, students management work is more complex, to further improve the level of the management work of students in Colleges and universities has become an important topic.

In this paper, we take college $\mathrm{S}$ as an example, combined with education theory and performance management evaluation theory, analysis college $\mathrm{S}$ students management situation and bulid the system index about college students management, through analysis of the evaluation results, put forward the reasonable improvement measures and suggestions, in order to promote problem solving.

\section{Performance Management Theory}

\subsection{Performance Management Theory Overview}

Performance management is the definition of basic objectives between managers and employees and how to achieve the goal of consensus management, achieving organizational goals through the help and encouragement of employees. The ultimate goal of performance management is to stimulate employees' enthusiasm and improve their own capacity and quality of the company's overall performance has improved.

The main factors affecting the performance of management is the external environment, internal conditions and the implementation of employee incentive effects. Organizations and individuals facing the external 
environment is an objective factor, which can not control; internal conditions refer to the job requirements of organizations and individuals to carry out a variety of resources.

\subsection{Students Work Performance Management Evaluation}

In the performance management of university students, the purpose is to improve the quality of students management staff, and urge them to do the work well. Therefore, when setting evaluation principles and evaluation indicators, we can not leave the actual student work management, performance management, especially leaving purpose. In other words, we must from the nature of the work involved in student administrator responsible for specific tasks, content, features and management objects, and many other reality, dialectically consider the evaluation objectives and training objectives, evaluation of the situation and working conditions, evaluation results and work effects, Then, in the actual evaluation work and earnestly implement the performance evaluation principle and index system, and strive for the purpose of performance evaluation can be achieved.

\section{ANP model}

Analytic Hierarchy Process is a professor SATTY proposed in 1996, it was developed on the basis of AHP on the formation of a new method of practical decision-making, especially for the presence of a complex decision-making system of internal interdependence and feedback effects. Decision-making problems for complex systems, using ANP method to construct the network structure, each element of the network may affect each other mutual domination, using the "ultimate super matrix" of various interactions comprehensive analysis of the factors which blend weights.

\subsection{Establishment of Judgment Matrix and Sequencing} Vector

The relative importance of each index in the ANP system is given by Delphi method, and the standard of $1 \sim 9$ is generally adopted..
A network control layer elements in ANP is $\mathrm{B}_{1}, \mathrm{~B}_{2} \ldots \mathrm{Bm}$, The network layer element is $\mathbf{C}_{1}, \mathrm{C}_{2} \ldots \mathrm{C}_{\mathrm{N}}$, and $C j=c_{j k}(k=1,2 \ldots n)$. The elements of the element set $\mathrm{Ci}$ are analyzed according to their influence on the $c_{j k}$, that is, the matrix of the elements is constructed under the control criterion. Then the rank vector is obtained by the characteristic root $\left[\boldsymbol{W}_{i 1}^{(j k)}, \boldsymbol{W}_{i 2}^{(j k)}, \ldots \boldsymbol{W}_{i n}^{(j k)}\right]^{T}$, If the feature vector is passed through the consistency test, then it is written in matrix form, and the local weight vector matrix is obtained.

$$
W_{i j}=\left[\begin{array}{cccc}
\boldsymbol{W}_{i 1}^{(j 1)} & \boldsymbol{W}_{i 1}^{(j 2)} & \cdots & \boldsymbol{W}_{i 1}^{(j m)} \\
\boldsymbol{W}_{i 2}^{(j 1)} & \boldsymbol{W}_{i 2}^{(j 2)} & \cdots & \boldsymbol{W}_{i 2}^{(j m)} \\
\cdots & \cdots & \cdots & \cdots \\
\boldsymbol{W}_{i m}^{(j 1)} & \boldsymbol{W}_{i m}^{(j 2)} & \cdots & \boldsymbol{W}_{i m}^{(j m)}
\end{array}\right](1)
$$

\subsection{Establishment of Hyper Matrix}

Similarly, compared with the internal and external relations of other elements, and the right weight hyper matrix is obtained by the rank vector which is influenced by each element in the network layer is $W_{s}$.

$$
W_{s}=\left[\begin{array}{cccc}
W_{11} & W_{12} & \ldots & W_{1 N} \\
W_{21} & W_{22} & \ldots & W_{2 N} \\
\ldots & \ldots & \ldots & \ldots \\
W_{N 1} & W_{N 2} & \ldots & W_{N N}
\end{array}\right] \text { (2) }
$$

Each element of the matrix is a matrix, and column is 1 ; but $\mathrm{W}$ is not normalized matrix. In order to facilitate the calculation, we need super matrix column normalization, namely weighting Ws of the elements to obtain a weighted hypermatrix.

\subsection{Ultra-weighted Matrix Calculation}

Bs guidelines under the control layer, the network layer of each group elements on $\mathrm{Cj}(\mathrm{j}=1, \ldots, \mathrm{N})$ compares the importance to give a sort of normalized vectors is $h_{i j}$, so $H_{j}=\left[\begin{array}{lll}h_{1 j} & \ldots & h_{N j}\end{array}\right]^{T}$

And then we can get the weight matrix. 
$H=\left[\begin{array}{ccc}h_{11} & \ldots & h_{1 j} \\ \ldots & \ldots & \ldots \\ h_{N 1} & \ldots & h_{N N}\end{array}\right](3)$

The matrix $\mathrm{H}$ and $\mathrm{W}$ is multiplied by the weighting hypermatrix $\bar{W}$.

\subsection{Hypermatrix W Stabilization Process}

Limit the stabilization process that is calculated relative ordering of each super-matrix vector:

$$
W^{\infty}=\lim _{h \rightarrow \infty}(1 / N) \sum_{k=1}^{N} \bar{W}^{k}
$$

Thus calculated index weights, and a prerequisite for a stable weight value matrix corresponding to the original line of each index is the ultimate convergence and unique.

\subsection{Standardized Indicators}

Positive indicators and reverse indicators were chosen formula (5) and (6) processing.

$$
\begin{aligned}
& s_{i}=\frac{x_{i}-\min x_{i}}{\max x_{i}-\min x_{i}}(5) \\
& s_{i}=\frac{\max x_{i}-x_{i}}{\max x_{i}-\min x_{i}}
\end{aligned}
$$

\subsection{Linear Weighted Method to Calculate the}

\section{Evaluation Value}

Summary Linear Model Selection indexes normalized index value to obtain a composite score.

$$
Y=\sum_{j=1}^{n} w_{j} s_{j} \quad \sum_{j=1}^{n} w_{j}=1, \propto \leq w_{j} \leq
$$

In this formula, $Y$ represents Integrated scores, $S_{j}$ represents Index value, $w_{j}$ represents weighting factor.

\section{College Students Work Performance Evaluation Model Based on ANP}

\subsection{Principles of College Students Work Performance Evaluation System}

(1)objectivity

Student work management staff assessment not only to examine their ideological and political quality, professional ethics, discipline, team spirit, ability to work, but also examine their actual work performance. To do a comprehensive assessment under the premise of work focusing on assessing student work performance management, highlighting the assessment of performance.

(2) leadership

College leaders should attach great importance to students' management team building, problems and shortcomings for evaluation of the results to be reflected in timely, The results of the assessment should be warm and helpful, to improve the opportunity to improve. The school should give praise and reward to the individual who should finish the work of the assessment, accomplish the good department and evaluate the outstanding results..

(3)right direction

Evaluation index should fully reflect the direction of running a school and personnel training requirements.Through the assessment and evaluation, guide students work management staff to understand the ideological unity. Mobilize the majority of students to work management staff to do a good job students management initiative and creativity.

(4) combining feasibility and practicality

The feasibility of the performance appraisal means that the evaluation act should have the operability of the reality, the people, the money, the material resources and the time condition should be available, so that the evaluation should be as full as possible. Feasibility is an important factor to develop the performance evaluation program, which is the important embodiment of the scientific evaluation of the program.. The practicability of the performance appraisal means that the results of the 
evaluation should have practical value and can bring significant positive effect to the staff.

\subsection{Establishment of College Students Work Performance System Index}

In this paper, take $\mathrm{S}$ college as an example, establish the university student work performance evaluation model based on ANP, and all indexes from the university student workers perspective.Index system establishment as shown in Table 1.

Tab.1. college students work performance system index

\begin{tabular}{|c|c|c|}
\hline \multirow{13}{*}{$\begin{array}{c}\text { Comprehensive Evaluation System } \\
\text { of S College Students Work } \\
\text { Performance (C) }\end{array}$} & \multirow{5}{*}{ Daily management $\left(\mathrm{C}_{1}\right)$} & Class attendance $\left(\mathrm{C}_{11}\right)$ \\
\hline & & Holidays on duty attendance $\left(\mathrm{C}_{12}\right)$ \\
\hline & & Student records management $\left(\mathrm{C}_{13}\right)$ \\
\hline & & Class Work perfection degree $\left(\mathrm{C}_{14}\right)$ \\
\hline & & $\begin{array}{l}\text { Student dormitory empty rate } \\
\left(\mathrm{C}_{15}\right)\end{array}$ \\
\hline & \multirow{2}{*}{$\begin{array}{l}\text { Ideological and Political Education } \\
\left(\mathrm{C}_{2}\right)\end{array}$} & Leadership degree of attention $\left(\mathrm{C}_{21}\right)$ \\
\hline & & Advanced caucus construction $\left(\mathrm{C}_{22}\right)$ \\
\hline & \multirow{3}{*}{ Construction of study style $\left(\mathrm{C}_{3}\right)$} & Honesty test pass rate $\left(\mathrm{C}_{31}\right)$ \\
\hline & & Pass rate of each course $\left(\mathrm{C}_{32}\right)$ \\
\hline & & Patent \&Contest winning rate $\left(\mathrm{C}_{33}\right)$ \\
\hline & \multirow{3}{*}{ Practice Associations $\left(\mathrm{C}_{4}\right)$} & Staff attendance $\left(\mathrm{C}_{41}\right)$ \\
\hline & & Activity effect $\left(\mathrm{C}_{42}\right)$ \\
\hline & & Activity richness $\left(\mathrm{C}_{43}\right)$ \\
\hline
\end{tabular}

\subsection{A case of study}

In this paper, take 5 departments(A,B,C,D,E) of a college as an example, and we used Super Decisions software to students work performance evaluation system, The relationship between the indexes was graded by nine points. By Super Decisions software, we can conclude that evaluation index weight at all levels. Among them, the final weight of the weight through the two indicators and the corresponding level of weight multiplied. According to formula (5)and (6), Finally, the results of the final evaluation are obtained by using the linear weighting method, as shown in Table 2.

Tab.2.Ultimate evaluation results

\begin{tabular}{|l|l|l|l|l|l|}
\hline & A & B & C & D & E \\
\hline results & 0.72 & 0.81 & 0.79 & 0.77 & 0.85 \\
\hline ranking & 5 & 2 & 3 & 4 & 1 \\
\hline
\end{tabular}

\section{Conclusion}

(1)strengthen the importance of the students in the performance level of student work management

School related leadership should be clear about the performance level of the students job management for the school as a whole strategy to achieve the important role. The students work management team is the core of education management, the center of the students service, the construction of the college counselor team in $\mathrm{S}$ should be gradually realized.

(2)establish and improve the relevant regulations of the students' political work

Set up and improve the students' ideological and political work of the relevant rules and regulations, cooperate with college related department school spirit, the rules and the construction of study style.Design all kinds of moral education activities, carry out the policy education situation and various kinds of ideological education activities. Scientifically and systematically carry out the psychological health education and 
psychological counseling for students, and pay more attention to some students.

\section{References}

[1] Tang Jie. A Doctor Dissertation (Master Thesis or Master Research Report) Submitted to University of Electronic Science and Technology of China [J]. Journal of UESTC, 2013.

[2] XU Zhi - yong. The Application of ANP -based multi - level fuzzy comprehensive evaluation methods topost - evaluation for grid construction projects [J]. Journal of East China Electric Power, 2009 (3) : 488-490.

[3] Xiao yezhi. Research on performance evaluation of student work management in Hunan finance and economic institute [D]. central south university, 2011. 